\title{
AVALIAÇÃO ERGONÔMICA EM AMBIENTES DE APRENDIZAGEM COM RECURSOS TECNOLÓGICOS, COMPARAÇÃO ENTRE ESTUDOS DE CASO DE RECIFE E NÁPOLES
}

\author{
SARMENTO, Thaisa F. C. Sampaio (1); \\ VILLAROUCO, Vilma (2) \\ (1) Universidade Federal de Alagoas, Doutora \\ e-mail: thaisa.sampaio@fau.ufal.br \\ (2) Universidade Federal de Pernambuco, Doutora \\ e-mail: villarouco@hotmail.com
}

\begin{abstract}
RESUMO
As escolas passam por mudanças metodológicas advindas da inserção de novas tecnologias. Os ambientes escolares também deverão ser atualizados, para que as atividades de aprendizagem com recursos tecnológicos sejam realizadas em plenas condições de conforto e ergonomia. Esta pesquisa realizou uma avaliação ergonômica em duas salas de aula enriquecidas com recursos tecnológicos, em escolas de ensino médio, no Brasil e na Itália. O método de avaliação foi baseado na MEAC Metodologia Ergonômica para o Ambiente Construído. Os resultados encontrados apontaram para diretrizes ergonômicas de readequação destes ambientes, visando também serem utilizados em aplicações de caráter prático, em outros projetos.
\end{abstract}

Palavras chave: Ergonomia do Ambiente Construído; Ambiente Escolar; Recursos tecnológicos e Estudos de caso.

\begin{abstract}
Schools go under methodological changes, that come from new technologies insertion. School environments should also be updated so that learning activities and technological resources could be carried out in full comfort and ergonomic conditions. This research shown an ergonomic evaluation in two classrooms technologically enriched, in high schools from Brazil and Italy. The evaluation method was based on MEAC - Ergonomic Methodology for the Built Environment. The results pointed to ergonomic guidelines for readjustment of these environments, aiming also to be used in practical applications, in other projects.
\end{abstract}

Keywords: Ergonomics of the Built Environment; Learning environment; Technological resources and Case studies.

\section{INTRODUÇÃO}

É momento de abrir caminho para as mudanças tecnológicas e comportamentais que decorrem da cybercultura, e assim, conectar as escolas com a realidade digital que vivenciamos. E fundamental que o sistema de ensino esteja mais voltado a contemporaneidade, o estudante deve estar no centro da sua própria aprendizagem, com maior autonomia e amplo acesso aos recursos digitais de aprendizagem.

O ambiente construído da escola deve estar preparado para as atualizações necessárias, exigidas pelos novos comportamentos, novas atividades e o reconhecimento da importância das aprendizagens múltiplas. Estas mudanças invariavelmente envolvem tecnologia e maior 
autonomia do estudante. Para Sibilia (2012), uma escola que não forma cidadãos para a recepção e utilização crítica das Tecnologias Midiáticas e Digitais de Informação e Comunicação (TMDICs) é a maior contradição existente no sistema educacional, já que novas gerações de estudantes deixam a escola sem qualquer preparação para realizar, de forma reflexiva e critica, as atividades as quais dedicam um maior número de horas: assistir televisão, navegar na internet, ou até mesmo, brincar com jogos eletrônicos.

O desafio para a questão do ambiente de aprendizagem é a necessidade de repensar e readequar suas funções e configurações, com base nas atividades que requerem equipamentos e recursos tecnológicos. Quando se constrói uma nova escola, é comum que as escolhas projetuais priorizem o critério do menor preço, para todas as escolhas referentes a materiais construídos, equipamentos e mobiliário. Há também uma forte desatualização dos ambientes escolares, pois a pouca profundidade de normas técnicas brasileira colabora com a existência de projetos pouco detalhados, ou que consideram apenas dimensionamentos e especificações mínimas. As salas de aula tradicionais são planejadas apenas para atividades expositivas, nas quais o professor fica junto à lousa, e os estudantes se agrupam em cadeiras e mesas de frente a lousa. Quanto aos recursos tecnológicos, quando existem são instalados de modo adaptado, sem preocupação em relação à melhor acomodação ou ao conforto dos usuários.

Este artigo é parte da Tese de Doutorado em Design intitulada de Modelo Conceitual de Ambiente de Aprendizagem adequado a Blended Learning para escolas de ensino médio, e objetiva analisar comparativamente dois ambientes de aprendizagem dotados de recursos computacionais em duas escolas de ensino médio.

\section{METODOLOGIA}

O método de coleta de dados foi baseado na MEAC - Metodologia Ergonômica para o Ambiente Construído (Villarouco, 2009, 2011).

\section{Quadro 1 - Descrição da MEAC - Metodologia Ergonômica para o Ambiente Construído.}

\begin{tabular}{|c|c|c|}
\hline ETAPAS & & OBJETIVOS \\
\hline \multirow{4}{*}{ FASE 1} & $\begin{array}{c}\text { ANÁLISE GLOBAL } \\
\text { DO AMBIENTE }\end{array}$ & Entender o sistema ambiente-humano-atividade numa abordagem macro \\
\hline & \multirow{2}{*}{$\begin{array}{l}\text { IDENTIFICAÇÃO } \\
\text { DA } \\
\text { CONFIGURAÇÃO } \\
\text { AMBIENTAL }\end{array}$} & Identificar e mensurar as condições dos fatores físicos e ambientais \\
\hline & & $\begin{array}{c}\text { Obter informações de ordem física e organizacional, assim como } \\
\text { descrições das tarefas prescritas }\end{array}$ \\
\hline & $\begin{array}{l}\text { AVALIAÇÃO DO } \\
\text { AMBIENTE EM } \\
\text { USO }\end{array}$ & $\begin{array}{c}\text { Analisar de modo sistemático as interferências dos condicionantes } \\
\text { espaciais no desempenho da atividade. Verificar a adequabilidade do } \\
\text { espaço a que o usuário } \\
\text { está sujeito, fluxos, usabilidade e mobilidade. }\end{array}$ \\
\hline \multirow[t]{2}{*}{ FASE 2} & $\begin{array}{l}\text { PERCEPÇÃO } \\
\text { AMBIENTAL }\end{array}$ & $\begin{array}{l}\text { Identificar os desejos e necessidades dos usuários para } \\
\text { o ambiente que utiliza, para uso utiliza técnicas da percepção ambiental }\end{array}$ \\
\hline & \multicolumn{2}{|c|}{$\begin{array}{l}\text { DIAGNOSTICO | RECOMMENDAÇÕES ERGONÔMICAS } \\
\text { Comparação da qualidade espacial das instituições investigadas e a interferência do ambiente na } \\
\text { qualidade de vida de seus usuários. As recomendações objetivam propor melhorias para os } \\
\text { ambientes analisados, buscando uma melhor adequação do ambiente ao usuário, permitindo } \\
\text { melhor desempenho do sistema ambiente-humano-atividade. }\end{array}$} \\
\hline
\end{tabular}

Fonte: Baseado em Villarouco et al. (2009, 2011).

A MEAC consiste em uma avaliação ergonômica que busca identificar conflitos ocasionados por elementos ausentes ou inadequados no ambiente, a partir das opiniões e sugestões dos próprios usuários, que são identificados através dos instrumentos de pesquisa da 


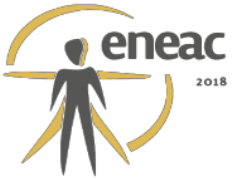

ergonomia, arquitetura e psicologia ambiental. Seu ponto de partida é a Análise Ergonômica do Trabalho - AET, e desenvolve-se em quatro grandes etapas: Análise física; Análise da percepção do usuário; Diagnóstico ergonômico, e; Proposições Ergonômicas para o Ambiente (quadro 1).

\subsection{Critérios para seleção da amostra}

As duas escolas analisadas foram selecionadas por critérios de acesso das pesquisadoras, e por apresentarem ambientes em que recursos computacionais são utilizados para fins de aprendizagem, com orientação presencial de um professor. As escolas selecionadas foram Liceo Statale Don Lorenzo Milani, em Nápoles, Itália, e Escola Técnica Cícero Dias, em Recife, Brasil. As coletas de dados aconteceram entre abril e junho de 2017.

\section{REVISÃO DE LITERATURA}

Powell (2015), Kaup, Kim \& Dudek (2013) e Baker (2011) apontam que o desempenho de estudantes na escola tem relação com a qualidade do edifício. Um edifício escolar mais antigo, atualmente, atrapalha a real entrada na educação do século XXI, principalmente com relação à flexibilização dos espaços e adoção de TICs. Entretanto, num projeto inovador contemporâneo, um edifício escolar bem projetado pode funcionar como catalisador de mudanças pedagógicas (OBLINGER, 2006). A reconfiguração espacial é uma tendência em projetos de escolas na Europa e nos EUA. Destaca-se a rede Vittra, na Suécia, com mais de 30 unidades escolares, que utilizam métodos educativos inovadores, espaços educacionais flexíveis e sem divisões internas.

Concordando com Tibúrcio (2005), Kowaltoski (2011), Guidalli (2012) e Nair (2014), o projeto de sala de aula deva ser concebido pelas necessidades de seus usuários. Dentre estas necessidades, destacam-se: espaços internos mais flexíveis para que as salas de aula, com vãos mais amplos, possam ser redimensionadas, com acessibilidade; os layouts precisam atender à atividade pedagógica proposta; o mobiliário precisa auxiliar as atividades pedagógicas e deve ser escolhido baseado no tipo de didática utilizada; num mesmo ambiente sejam oferecidos mobiliários diferentes, permitindo a variação de arranjos, além de dar a opção de o aluno escolher o que mais lhe agrada e lhe dá conforto; os professores precisam de instruções para a utilização correta dos equipamentos e, em cada sala, deve haver instruções práticas para o uso de cada equipamento instalado; os espaços precisam ser atraentes e confortáveis. Huang et al. (2012) propõem a configuração de sala de aula inteligente (smart classroom), em que o layout se relaciona com a otimização da apresentação do conteúdo de ensino, o livre acesso a recursos de aprendizagem, a interatividade com recursos de ensino e de aprendizagem, o layout e a gestão da sala de aula.

\section{AS ESCOLAS ANALISADAS}

\subsection{Escola Técnica Cícero Dias (ETE-CD) em Recife}

A Escola Técnica Estadual Cícero Dias (ETE-CD) inalgurada em 2006, oferecendo Ensino Médio Profissionalizante na modalidade integral (figura 1). A parceria com o Instituto Oi Futuro tem como missão criar metodologias inovadoras de ensino e aprendizagem em diálogo com as tecnologias da informação e da comunicação, com o intuito de explorar e discutir o cotidiano da vida, dentro da sala de aula, aproximando os estudantes da realidade 


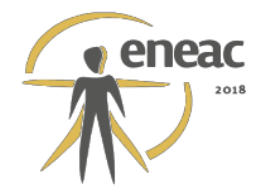

circundante. Em 2017, a escola contava com 452 estudantes, que frequentam a escola de maneira totalmente gratuita. Todos os anos são oferecidas 180 novas vagas, através de seleção pública para jovens entre 14 e 17 anos. A maioria das vagas são destinadas a jovens oriundos de escolas públicas, e a forma de seleção é por prova escrita de conteúdos de português e matemática. Nesta escola são oferecidos dois cursos - Programação de Jogos e Multimídia.

Figura 1 - Escola Técnica Estadual Cícero Dias (a) Pátio interno durante um ensaio dos estudantes, (b) Estudantes observados em aula dotada de recursos computacionais.

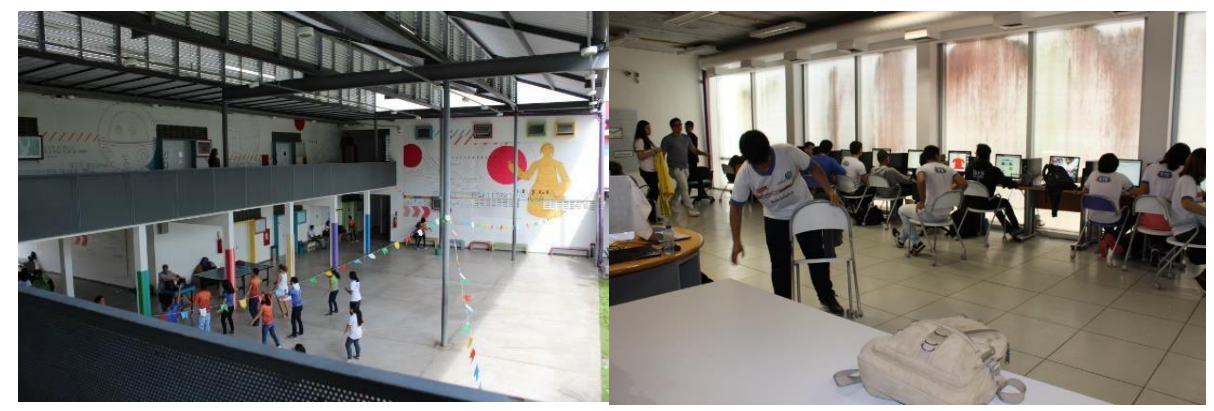

Fonte: As Autoras.

\subsection{Liceo Statale Don Lorenzo Milani (LS-DLM) em Nápoles}

O Liceo Statale Don Lorenzo Milani é localizado ao centro do distrito de San Giovanni a Teduccio, em Nápoles, Itália. Suas instalações físicas (Figura 2) são compostas por dois blocos de dois pavimentos, conjugados por uma circulação interna. O método de ensino associa ensino tradicional com recursos digitais em algumas disciplinas, para isso, as salas de aula são amplas e dotadas de internet. A escola é pública e atende a cerca de 790 estudantes, distribuídos em 39 turmas, com 20 estudantes em média, por turma. Seu projeto pedagógico oferece: formação em línguas, artes visuais e arquitetura.

Figura 2 - Liceo Statale Don L. Milani (a) Circulação interna (b) durante a aula, na sala de informática.

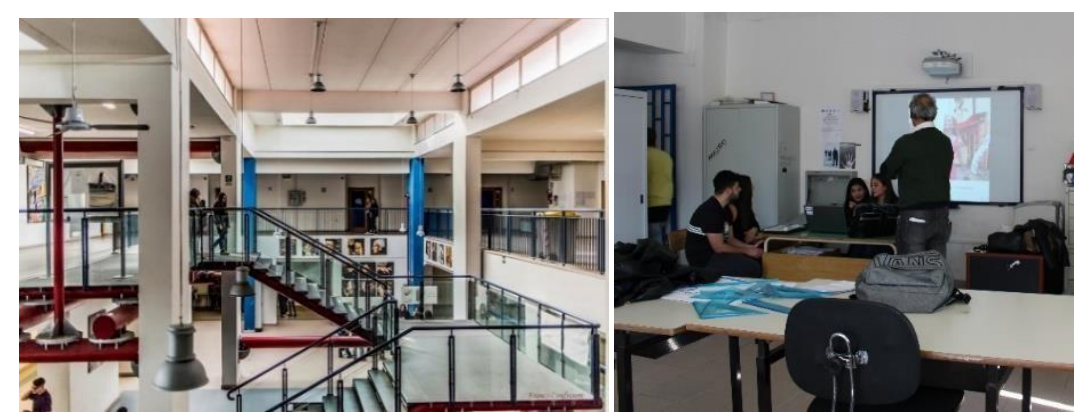

Fonte: As Autoras.

\section{ANÁLISE DOS DADOS}

Os dados foram coletados e analisados para cada um dos estudos de caso realizados, e encontram-se descritos de acordo com as etapas da MEAC, nos itens a seguir.

\subsection{Análise Global dos Ambientes}




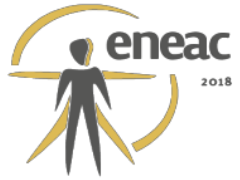

Em ambas as escolas, a maioria das salas de aula são expositivas. Se uma disciplina exige o uso de computadores para pesquisa, ou trabalhos digitais, as turmas usam uma sala específica de computadores. Em atividades de grupo, a reorganização do layout torna-se uma barreira, móveis grandes e pesados, ou o pouco espaço livre dificultam atividades mais dinâmicas. Percebe-se que em ambas as escolas, a sala de computadores é uma adaptação por oferecer um amplo espaço, mas a configuração do layout foi determinada pela forma arquitetônica, e não pelas atividades que seriam desempenhadas nos ambientes, portanto foram identificadas inadequações em relação a condições mínimas de conforto, fluxo, ergonomia e satisfação dos usuários.

\subsection{Identificação da Configuração Ambiental}

Os dados dimensionais e funcionais observados nas salas de aula foram registrados pela pesquisadora em meio fotográfico e dimensional.

\section{Escola 1: ETE-CD}

Área útil do ambiente: $120,61 \mathrm{~m}^{2}$, considerando a capacidade máxima de ocupação (28 pessoas em computadores) tem-se a relação $4,30 \mathrm{~m}^{2} /$ estudante, considerada excessiva, uma vez que a relação sugerida pela Fundescola (2012) é de 1,5 $\mathrm{m}^{2} /$ estudante. Há espaço ocioso, mesmo considerando a turma com 33 pessoas, a falta de concentração da turma é um problema constante.

Distribuição do mobiliário: Existem 19 mesas e 19 cadeiras com rodízios, junto a janelas, 04 mesas redondas com 03 cadeiras cada, para computadores, 02 mesas retangulares com 06 cadeiras cada para trabalhos em grupo; de frente a lousa, 01 mesa para o professor, 01 lousa digital com projetor suspenso no forro, 02 armários; e instalações de internet wi-fi, e de energia elétrica - tomadas e iluminação. 29 computadores fornecidos pela escola, sendo 01 destinado ao professor.

\section{Escola 2: LS-DLM}

Área útil do ambiente: $78,80 \mathrm{~m}^{2}$, considerando a capacidade máxima de ocupação (20 pessoas), tem-se a relação $3,94 \mathrm{~m}^{2} /$ estudante, considerada excessiva, uma vez que no Brasil, a relação sugerida pela Fundescola (2012) é de 1,5 $\mathrm{m}^{2} /$ estudante. Há espaço ocioso, e o tamanho e o peso do mobiliário são grandes problemas.

Distribuição do mobiliário: Existem 12 mesas e 12 cadeiras altas, ao centro; 04 mesas para 08 computadores, com 08 cadeiras em altura regular, junto à parede lateral; 02 mesas para apoio do orador (professor), de frente à lousa; 05 armários; 01 tela de projeção; 01 projetor suspenso no forro; e instalações de internet wi-fi e de energia elétrica - tomadas e iluminação.

Mensuração de índices de desempenho (ambos os ambientes): Foram utilizadas as ferramentas digitais: desempenho térmico - DS Thermometer (DS Software), desempenho acústico - Decibelímetro (Sound Meter, Abc Apps), e desempenho lumínico - Medidor de Luz O2 Led (www.o2led.com.br) (tabela 1).

Tabela 1 - Dados físicos obtidos nos ambientes analisados.

\begin{tabular}{|l|l|r|c|}
\hline $\begin{array}{l}\text { FATOR } \\
\text { ANALISADO }\end{array}$ & INDICE RECOMENDADO & $\begin{array}{r}\text { ÍNDICE OBTIDO } \\
\text { ESCOLA 1: ETE-CD }\end{array}$ & $\begin{array}{c}\text { ÍNDICE OBTIDO } \\
\text { ESCOLA 2: LS-DLM }\end{array}$ \\
\hline Temperatura & $23^{\circ} \mathrm{C}$ & 23 & 22 \\
\hline$\left({ }^{\circ} \mathrm{C}\right)$ & (Kowaltowski, 2011) & & \\
\hline
\end{tabular}




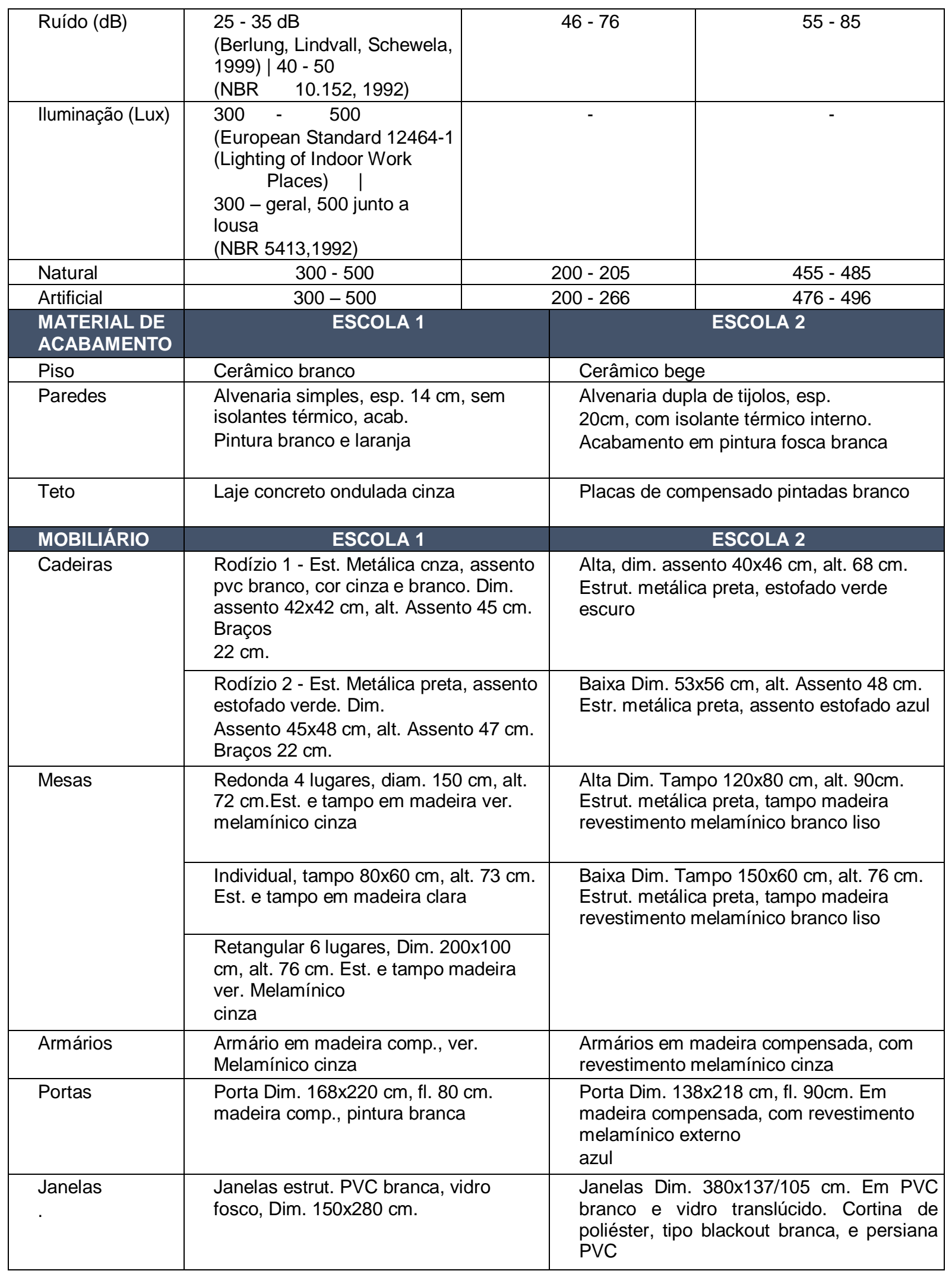

\subsection{Avaliação do Ambiente em Uso}

Para analisar as atividades desenvolvidas pelos usuários, foi elaborado um fluxograma de 
atividades, que mostra os 3 principais níveis de atividades relativas ao uso dos ambientes. 0 nível 1 trata de atividades de acesso e acomodação no ambiente, o nível 2 refere-se às atividades educacionais propriamente ditas, e o nível 3 refere-se às pequenas atividades de manuseio de instrumentos e ferramentas de trabalho, em cada macro atividade correlata. No quadro 2 (abaixo) são analisados os dados no Nível 1 de atividade em aula e demonstram a tarefa demandada ao usuário, as condições oferecidas pelos ambientes.

\section{Quadro 2 - Análise das atividades do nível 1 - Acesso e percurso em sala de aula}

\begin{tabular}{|c|c|c|}
\hline TAREFA & $\begin{array}{l}\text { CONDIÇÕES OFERECIDAS PELO } \\
\text { AMBIENTE } \\
\text { ESCOLA } 1 \text { ETE-CD }\end{array}$ & $\begin{array}{c}\text { CONDIÇÕES OFERECIDAS PELO } \\
\text { AMBIENTE } \\
\text { ESCOLA } 2 \text { LS-DLM }\end{array}$ \\
\hline ABRIR & $\begin{array}{l}\text { A largura da porta é de } 85 \mathrm{~cm} \text { e abre para o } \\
\text { exterior, que facilita em situações de fuga. É } \\
\text { feito de madeira, pintada de branco. A } \\
\text { maçaneta é formato de alavanca, com risco de } \\
\text { captura o punho de casacos }\end{array}$ & $\begin{array}{l}\text { A largura da porta é de } 90 \mathrm{~cm} \text { e abre para o } \\
\text { exterior, que facilita em situações de fuga. É } \\
\text { feito de madeira, com revestimento } \\
\text { melamínico, e não há visor. A maçaneta é } \\
\text { formato de bola, com botão de abertura, que } \\
\text { impede o enganche de casacos (risco de } \\
\text { captura o punho com a roupa) }\end{array}$ \\
\hline $\begin{array}{l}\text { ENTRAR } \\
\text { NA SALA }\end{array}$ & $\begin{array}{l}\text { A sala é ampla. Há espaço de aproximação } \\
\text { junto a porta, de onde se visualização toda a } \\
\text { sala de aula, antes de atravessa-la. O piso é } \\
\text { liso e plano e, portanto, corretamente-permite a } \\
\text { execução de movimentos em segurança. As } \\
\text { iluminações naturais ou artificiais são } \\
\text { adequadas ao desenvolvimento do caminhar. }\end{array}$ & $\begin{array}{l}\text { A sala é ampla. Há espaço de aproximação } \\
\text { junto à porta, de onde se visualizam toda a } \\
\text { sala de aula, antes de atravessá-la. O piso é } \\
\text { liso e plano e, portanto, corretamente- permite } \\
\text { a execução de movimentos em segurança. As } \\
\text { iluminações naturais ou artificiais são } \\
\text { adequadas ao desenvolvimento do caminhar. }\end{array}$ \\
\hline $\begin{array}{l}\text { ALCANÇAR } \\
\text { SEU } \\
\text { ASSENTO }\end{array}$ & $\begin{array}{l}\text { O layout da sala de aula tem duas } \\
\text { organizações: } 1 \text { - mesas individuais de frente a } \\
\text { janela lateral, e } 2 \text { - mesas para grupos junto a } \\
\text { parede lateral, todas as mesas para uso de } \\
\text { computadores desktop. }\end{array}$ & $\begin{array}{l}\text { O layout da sala de aula tem duas } \\
\text { organizações diferentes: } 1 \text { - espaço de bancos } \\
\text { altos ao centro para trabalhos manuais, e } 2 \text { - } \\
\text { espaço para uso de computadores desktop. }\end{array}$ \\
\hline $\begin{array}{l}\text { SENTAR- } \\
\text { SE }\end{array}$ & $\begin{array}{l}\text { Existem dois tipos de mesas/assentos na sala } \\
\text { de aula: } 1 \text { - mesas individuais na lateral, junto } \\
\text { a janela. Em frente a parede lateral direita (sem } \\
\text { janelas) há } 06 \text { mesas de grupo com } \\
\text { computadores (desktop). As cadeiras são } \\
\text { estofadas, ou em polietileno, com rodízio e } \\
\text { apoio de braços, em bom estado. }\end{array}$ & $\begin{array}{l}\text { Existem dois tipos de mesas/assentos na sala } \\
\text { de aula: } 1 \text { - ao centro da sala de aula, existem } \\
4 \text { fileiras de mesas/bancos altos, em que os } \\
\text { estudantes podem fazer o trabalho manual, } \\
\text { estudo, ou grupo. Em frente à parede lateral } \\
\text { direita (sem janelas) há uma fileira de } 06 \\
\text { mesas regulares com computadores } \\
\text { (desktop), onde os estudantes podem usar a } \\
\text { internet e fazer outros trabalhos de escola em } \\
\text { que você } \\
\text { precisa usar o seu pc. }\end{array}$ \\
\hline $\begin{array}{l}\text { ORGANIZA } \\
\text { R SEUS } \\
\text { OBJETOS } \\
\text { PESSOAIS }\end{array}$ & $\begin{array}{l}\text { Os armários existentes são utilizados para } \\
\text { armazenar trabalhos dos estudantes. Para os } \\
\text { objetos pessoais, eles usam armários } \\
\text { localizados no corredor. }\end{array}$ & $\begin{array}{l}\text { Os armários existentes são utilizados para } \\
\text { armazenar trabalhos dos estudantes. Para os } \\
\text { objetos pessoais, eles acomodam sobre as } \\
\text { mesas ou cadeiras, e então, no final da aula, } \\
\text { levam tudo de volta para casa. }\end{array}$ \\
\hline $\begin{array}{l}\text { FICAR DE } \\
\text { PÉ }\end{array}$ & $\begin{array}{l}\text { O movimento de levantar-se é feito livremente } \\
\text { e diversas vezes ao longo da aula. }\end{array}$ & $\begin{array}{l}\text { O movimento de levantar-se é feito livremente } \\
\text { e diversas vezes ao longo da aula. }\end{array}$ \\
\hline $\begin{array}{l}\text { SAIR } \\
\text { DA SALA }\end{array}$ & $\begin{array}{l}\text { Estudantes movem-se livremente, mas } \\
\text { somente saem da aula ao final. }\end{array}$ & $\begin{array}{l}\text { Estudantes movem-se livremente e saem da } \\
\text { aula diversas vezes. }\end{array}$ \\
\hline
\end{tabular}

No quadro 3 (abaixo) são analisados os dados no Nível 2 em ambos os ambientes analisados. 


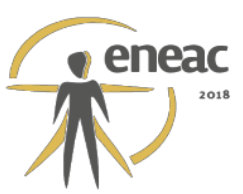

Quadro 3 - Análise do Nível 2 - Realizar atividades de aprendizagem em sala de aula

\begin{tabular}{|c|c|c|}
\hline TAREFA & $\begin{array}{l}\text { CONDIÇÕES OFERECIDAS } \\
\text { PELO AMBIENTE } \\
\text { ESCOLA } 1 \text { ETE-CD }\end{array}$ & $\begin{array}{c}\text { CONDIÇÕES OFERECIDAS PELO AMBIENTE } \\
\text { ESCOLA } 2 \text { LS - DLM }\end{array}$ \\
\hline $\begin{array}{l}\text { ASSISTIR UMA } \\
\text { APRESENTA } \\
\text { ÇÃO ORAL }\end{array}$ & $\begin{array}{l}\text { A sala está equipada com } \\
\text { ferramentas digitais para o } \\
\text { apresentação e conexão com } \\
\text { internet (Wi-Fi). Os alunos portam } \\
\text { suas cadeiras, até a frente da sala, } \\
\text { para assistir e ouvir a lição. }\end{array}$ & $\begin{array}{l}\text { A sala está equipada com ferramentas digitais para } \\
\text { apresentação e conexão com internet (Wi-Fi). Os } \\
\text { estudantes que se sentam mais perto da lousa digital, } \\
\text { usando mesas e cadeiras altas, veem e ouvem a lição } \\
\text { melhor do que os estudantes que estão sentados nas } \\
\text { últimas fileiras; ou mesmo, do que, quem está sentado } \\
\text { nas mesas de computadores, frente à parede, que não } \\
\text { podem ver a apresentação }\end{array}$ \\
\hline $\begin{array}{l}\text { TRABALHAR } \\
\text { INDIVIDUALM } \\
\text { ENTE SOBRE } \\
\text { MESA }\end{array}$ & $\begin{array}{l}\text { Existem três tipos de mesas na sala } \\
\text { de aula: junto da janela, há mesas } \\
\text { individuais, e junto a outra lateral há } \\
\text { mesas redondas, e retangulares. As } \\
\text { mesas individuais e redondas } \\
\text { acomodam desktops, e as mesas } \\
\text { retangulares podem acomodar } \\
\text { atividades de escrita e desenho } \\
\text { manual, de estudo ou em grupo. }\end{array}$ & $\begin{array}{l}\text { Existem dois tipos de mesas na sala de aula: ao centro } \\
\text { da sala de aula, existem quatro linhas de mesas com } \\
\text { cadeiras altas, onde o aluno pode fazer seu trabalho } \\
\text { manual, de estudo ou em grupo. Junto a parede } \\
\text { lateral, há mesas com cadeiras de altura regular, } \\
\text { equipados com computadores (desktop), onde o aluno } \\
\text { pode fazer uso da internet e outras atividades que } \\
\text { demandem uso de computadores }\end{array}$ \\
\hline \multirow[t]{2}{*}{$\begin{array}{l}\text { TRABALHAR } \\
\text { EM EQUIPE }\end{array}$} & \multirow{2}{*}{$\begin{array}{l}\text { O layout da sala de aula permite que } \\
\text { alunos usem mesas retangulares } \\
\text { para sentar-se, ao realizar atividades } \\
\text { de grupo, como leitura, escrita, } \\
\text { discussão ou atividades práticas. }\end{array}$} & $\begin{array}{l}\text { O layout da sala de aula permite usar apenas cadeiras } \\
\text { altas para sentar, para atividades manuais e também } \\
\text { de leitura, escrita ou práticas. }\end{array}$ \\
\hline & & $\begin{array}{l}\text { O layout da sala de aula permite que os estudantes } \\
\text { usam cadeiras regulares e fixas para mesas com } \\
\text { computadores desktop. Existem } 8 \text { mesas nessa área, } \\
\text { e não são suficientes para o número de estudantes. O } \\
\text { acesso à rede é bom com acesso wi-fi. }\end{array}$ \\
\hline $\begin{array}{l}\text { FAZER UMA } \\
\text { APRESENTA } \\
\text { ÇÃO }\end{array}$ & $\begin{array}{l}\text { O layout da sala de aula permite que } \\
\text { os estudantes em pé, falem de frente } \\
\text { a classe. O espaço frontal é } \\
\text { satisfatório. Há projetor e tela } \\
\text { adequados para executar esta tarefa. }\end{array}$ & $\begin{array}{l}\text { O layout da sala de aula permite que estudantes usem } \\
\text { apenas mesas altas para sentar-se, ao realizar } \\
\text { atividades de grupo, como leitura, escrita, discussão } \\
\text { ou atividades práticas. }\end{array}$ \\
\hline $\begin{array}{l}\text { ADEQUAR AS } \\
\text { CONDIÇÕES } \\
\text { DO AMBIENTE } \\
\text { ÀS } \\
\text { NECESSIDAD } \\
\text { ES } \\
\text { ESPECÍFICAS } \\
\text { DA } \\
\text { CLASSE }\end{array}$ & $\begin{array}{l}\text { A sala é equipada com sistema } \\
\text { elétrico suficiente para carregar os } \\
\text { desktops. lluminação artificial é } \\
\text { insuficiente, mas é uniforme. As } \\
\text { tomadas elétricas são utilizadas } \\
\text { somente para os desktops, e junto a } \\
\text { lousa, onde pode-se fazer ligar } \\
\text { instrumentos de projeção. } \\
\text { As janelas estão posicionadas em } \\
\text { duas paredes - em ambos os lados } \\
\text { da lousa. } \\
\text { A sala é equipada com armários para } \\
\text { acomodar material escolar, e } \\
\text { trabalhos dos estudantes. }\end{array}$ & $\begin{array}{l}\text { O layout da sala de aula permite que os estudantes em } \\
\text { pé, falem de frente à classe. O espaço frontal é } \\
\text { satisfatório. Há projetor e tela adequados para } \\
\text { executar esta tarefa. } \\
\text { A sala é equipada com armários para acomodar } \\
\text { material escolar e trabalhos dos estudantes. } \\
\text { A sala é equipada com sistema elétrico suficiente para } \\
\text { acionamento da iluminação artificial, controle de } \\
\text { temperatura por meio de calefação. } \\
\text { As janelas estão posicionadas em duas paredes - ao } \\
\text { lado da lousa e ao fundo da sala. Isto fornecem uma } \\
\text { boa visualização do exterior. Há una única cortina, na } \\
\text { sala de aula, próximo à lousa, que melhora a condição } \\
\text { de obscuridade para fazer projeções. } \\
\text { lluminação artificial é pouco adequada, mas é } \\
\text { uniforme. As tomadas elétricas são utilizadas somente } \\
\text { para os desktops, e também junto à lousa, onde se } \\
\text { pode fazer ligar instrumentos de projeção. }\end{array}$ \\
\hline
\end{tabular}

\section{Escola 1: ETE-CD}

Esta sala demonstrou as dificuldades de adequação espacial aos recursos computacionais, principalmente quanto ao dimensionamento e flexibilização dos assentos para mudança entre atividade expositiva e atividade individual em computador. A quantidade de estudantes da turma (33 pessoas), superior ao número de computadores (28 unidades), associado a amplitude excessiva do espaço, dificultaram o trabalho do professor, para expor o conteúdo, acompanhar cada estudante em seu exercício prático, e controlar a dispersão entre os estudantes. Para ouvir a lição, os estudantes empurraram suas cadeiras (com rodízios) até a frente da sala, em seguida 


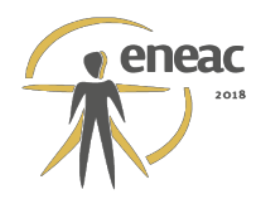

retornaram aos seus lugares. Os assentos não são fixos durante todo o ano, então os estudantes sentam nos lugares que os interessam por motivos de afinidades sociais. $O$ clima é bastante descontraído, e os estudantes demonstram interesse no conteúdo. Foi elaborada uma planta que demonstra os fluxos, a distribuição do layout e as formas de utilização do espaço. Na figura 3, em amarelo, estão destacadas as zonas de maior uso, de acordo com as atividades observadas: Atividade expositiva - concentração de pessoas de frente a lousa, e os estudantes trazem suas cadeiras para frente; Atividade de trabalho nos desktops - cadeiras e mesas individuais alinhados no perímetro da sala, e em mesas circulares em uma das laterais da sala. Em roxo, destacam- se as zonas de menor uso, nas extremidades ao fundo da sala, ou lateralmente à lousa. Os fluxos estão marcados em verde - para o acesso ao mobiliário, e em laranja para saída da sala. Esta sala foi preparada para acomodar 40 estudantes, mas há somente 31 desktops disponíveis. Assim os estudantes precisam fazer atividades sempre em duplas. $O$ formato muito alongado, causa áreas de pouca, ou nenhuma utilização, causando dispersão, e certa desatenção da turma para o professor.

\section{Figura 3 - Planta (sem escala) da sala de informática, demonstrando usos e fluxos - Escola} 1: ETE-CD.

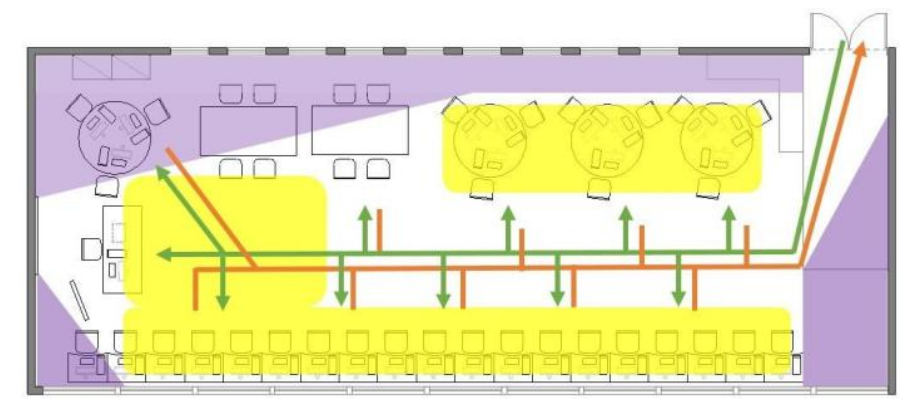

Fonte: As autoras.

\section{Escola 2: LS-DLM}

Num primeiro momento, o professor falava para a turma, e eles estavam reunidos ao centro da sala, nas mesas altas, onde também deixaram suas bolsas e pertences pessoais. A atividade demandada pelo professor foi individual, ao computador - desktop. O professor autorizou a turma a ouvir música, durante a atividade em sala. O professor realizou orientações individuais aos estudantes, de mesa em mesa, enquanto eles executavam 0 exercício. Alguns estudantes saiam da sala com frequência $e$ demonstraram desinteresse, mantendo uma conversa informal constante com colegas. A falta de computadores para todos os estudantes contribuiu para a dispersão, pois nem todos puderam fazer o exercício. O relacionamento entre estudantes e professores pareceu ser tranquilo e aberto, mesmo notada a dispersão, que aumentou ao final da aula.

Foi elaborado um mapa de fluxo e uso da sala analisada (figura 4). Em amarelo, estão destacadas as zonas de maior uso - ao centro da sala, para atividades individuais ou em grupos; junto à lousa em apresentações orais; e junto à parede da esquerda, mesas para uso dos computadores desktops. Em roxo, destacam-se as zonas de menor uso - ao fundo da sala, de onde não se consegue ver a lousa, nem ouvir a palavra falada, com clareza, e lateralmente a lousa, formando uma pequena zona junto da janela, com cortina. Essas zonas em roxo, por terem menos uso, acumulam material de trabalho e de descarte. Os fluxos estão marcados em verde - para o acesso ao mobiliário, e em laranja para saída da sala. 
Figura 4 - Planta (sem escala) da sala de informática, demonstrando usos e fluxos - Escola 2: LS- DLM.

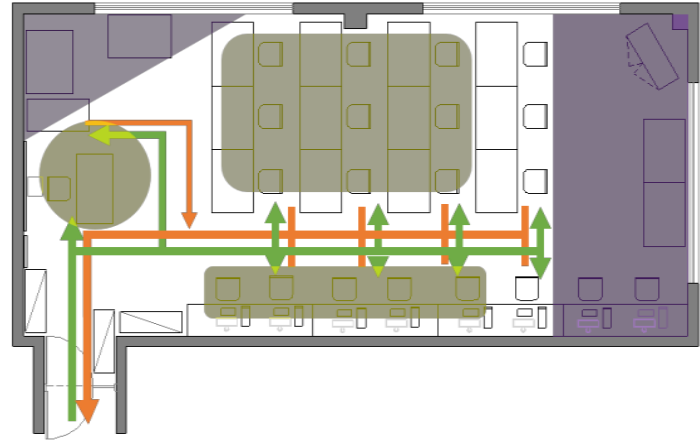

Fonte: As Autoras.

\subsection{Análise da Percepção do Usuário}

Para coletar a percepção do usuário sobre o ambiente vivenciado, foi aplicada a técnica de Brainstorming. Os resultados apontaram a satisfação dos estudantes, de acordo com suas preferências pessoais e culturais (Quadro 4).

Quadro 4 - Síntese da percepção dos usuários nas duas escolas analisadas.

\begin{tabular}{|c|c|}
\hline ESCOLA 1 ETE-CD & ESCOLA 2 LS-LM \\
\hline \multicolumn{2}{|c|}{ QUE COISAS VOCÊS GOSTAM NESTA SALA DE AULA? } \\
\hline $\begin{array}{l}\text { Espaço amplo; uso de cores; computadores } \\
\text { disponíveis o tempo todo; diferentes formas de } \\
\text { organização de cada sala; ar condicionado e } \\
\text { multimídia nas salas; boa iluminação; bom } \\
\text { relacionamento entre as pessoas }\end{array}$ & $\begin{array}{l}\text { A amplitude e a iluminação da sala de aula; a disposição } \\
\text { dos bancos; os corredores espaçosos; poder usar } \\
\text { recursos de multimídia; excelente relacionamento entre } \\
\text { estudantes e professores }\end{array}$ \\
\hline \multicolumn{2}{|c|}{ QUE COISAS VOCÊS NÃO GOSTAM NESTA SALA DE AULA? } \\
\hline $\begin{array}{c}\text { Porta objetos debaixo das cadeiras; velocidade baixa } \\
\text { da internet; cadeiras são desconfortáveis e pequenas; } \\
\text { muita conversa durante a aula; lousas digitais que não } \\
\text { funcionam; salas muito fechadas, sem aberturas para } \\
\text { o exterior; pouca luz natural; mesas danificadas; ar- } \\
\text { condicionado ineficiente; tamanho da lousa pequeno; } \\
\text { infiltrações nas paredes }\end{array}$ & $\begin{array}{l}\text { Temperatura interna desconfortavel no verão e no } \\
\text { inverno; limpeza são precárias; pouco material para } \\
\text { trabalhos práticos e mal exibição dos trabalhos } \\
\text { escolares; distribuição ruim do espaço; } \\
\text { isolamento acústico e térmico ruins; } \\
\text { não são usados espaços ao ar livre; infiltração nas } \\
\text { paredes; computadores insuficientes para o número } \\
\text { de estudantes; portas sem manutenção; armários e } \\
\text { materiais insuficinentes; internet limitada. }\end{array}$ \\
\hline \multicolumn{2}{|c|}{$\begin{array}{l}\text { SE VOCÊS PUDESSEM PROJETAR UMA NOVA SALA DE AULA, } \\
\text { QUE COISAS PODERIAM MELHORAR? }\end{array}$} \\
\hline $\begin{array}{l}\text { EM RELAÇÃO À ESCOLA: } \\
\text { Ter mais momentos de troca de opiniões com os } \\
\text { estudantes, ter mais ajuda com seus problemas; } \\
\text { Sempre ter aulas dinâmicas. }\end{array}$ & $\begin{array}{c}\text { EM RELAÇÃO À ESCOLA: } \\
\text { Ter cafeteria ou lanchonete; permitir a criatividade } \\
\text { artística nas paredes; permitir uso livre da biblioteca } \\
\text { para estudar sozinho; ter computadores e Wi-Fi livre; } \\
\text { instalar espelhos nos banheiros; } \\
\text { permitir espaços para fumantes; melhorar a limpeza } \\
\text { dos banheiros; permitir/criar saída e acesso aos jardins, } \\
\text { ou área para relaxamento para fins de } \\
\text { convivência; exposição de trabalhos dos estudantes } \\
\text { também no Bloco B; melhorar as máquinas de } \\
\text { alimentos/ bebidas no Bloco B; } \\
\text { melhorar a manutenção do jardim e do ginásio. }\end{array}$ \\
\hline $\begin{array}{l}\text { EM RELAÇÃO À SALA DE AULA: } \\
\text { Cadeiras estofadas, llousa maior; colocaria tabelas } \\
\text { com as fórmulas nas paredes; ter aparelhos de ar- } \\
\text { condicionado mais eficientes e em bom estado de } \\
\text { manutenção; usar as lousas digitais; ter espaço e } \\
\text { momento para descanso e soneca. }\end{array}$ & $\begin{array}{c}\text { EM RELAÇÃO À SALA DE AULA: } \\
\text { Permitir o uso de telefones celulares para fins de } \\
\text { aprendizagem; instalar mais tomadas de energia; } \\
\text { adquirir móveis e equipamentos novos; permitir pintar } \\
\text { as paredes coloridas; instalar mais cortinas nas janelas; } \\
\text { oferecer mais materiais para trabalhos } \\
\text { práticos; permitir integração com área verde, jardins; } \\
\text { maior interatividade com internet em aula. }\end{array}$ \\
\hline
\end{tabular}




\subsection{Diagnóstico e proposições ergonômicas}

\section{Diagnóstico ergonômico geral}

Em ambos os ambientes analisados foram encontradas inadequações quanto a: qualidade construtiva e manutenção, condições de limpeza, instalações elétricas. Do ponto de vista do mobiliário, a diversidade de móveis é satisfatória, mas percebe-se que não houve critério ergonômico para escolha e aquisição dos moveis em uso. Os níveis de iluminação na área de trabalho também apontaram inadequações em relação a necessidade de luz de tarefa sobre as mesas, quanto ao aproveitamento/proteção da iluminação natural direta.

O maior problema encontrado foi a percepção de que o layout dos ambientes são adaptações, e não foram planejados para receberem atividades com recursos tecnológicos, também não oferecem a flexibilidade necessária a múltiplas atividades variações entre aulas expositivas, aulas práticas com auxílio do professor, atividades individuais e atividades em grupo. O mesmo formato retangular muito alongado, e a disposição do mobiliário favorecem a dispersão da turma, e áreas de maior concentração de pessoas. As condições do mobiliário são de inadequação ergonômica, desgaste, má iluminação em mesas de trabalho, mau posicionamento das telas dos desktops em relação à lousa, e em relação às janelas, causando ofuscamento. Há pouca proteção das aberturas contra iluminação direta. Soma-se a esses problemas, na escola brasileira turmas muito numerosas, e um único professor para conduzir a aprendizagem.

\section{Proposições ergonômicas gerais}

Com base nas análises realizadas nos ambientes analisados, foram elaboradas diretrizes ergonômicas para ambientes de aprendizagem enriquecidos em tecnologia (Quadro 5).

\section{Quadro 5 - Síntese de Requisitos Ambientais e Ergonômicos propostos para o Modelo Conceitual de Ambiente de Aprendizagem adequado ao blended learning.}

\section{AMBIENTE CONSTRUÍDO}

Instalar portas de acesso ao fundo da sala, evitando desconcentrar a turma em relação à lousa; fornecer tomadas elétricas bem distribuídas para carregar instrumentos digitais dos estudantes em suas mesas; instalar portas com visores, e numa posição que não tire, nem atrapalhe a atenção e a visualização da lousa instalar banheiros próximos às salas - masculino e feminino, evitando longas distâncias para alcançar banheiros coletivos, assim como áreas de convivência ao ar livre; Posicionar janelas para o exterior - amplas e adequadas ao melhor aproveitamento da incidência solar, e para o corredor, permitindo a livre visualização dos espaços; permitir personalizar cores e grafismos nas paredes da escola, e das salas de aula, favorecendo a sensação de jovialidade e acolhimento, valorizados pelos entrevistados; forma do ambiente que proporcione um layout mais dinâmico e flexível, favorecendo a concentração e o conforto visual no uso de telas de computador.

\section{CONDIÇŌES DE CONFORTO}

Proporcionar condições adequadas de visibilidade e de audibilidade do conteúdo em exposição (Gee, 2006); pintar parede da lousa num tom mais escuro permitindo focar o olhar na lousa; garantir boas condições de conforto psicológico, senso de identidade e de segurança; adequar o ambiente para atender às condições de conforto, de acordo com as estações do ano. Proporcionar sensação térmica adequada no inverno, ou no verão, e de acordo com as recomendações técnicas internacionais.

\section{LAYOUT E MOBILIÁRIO}

Posicionar mesas e cadeiras, inclusive com desktops de frente à lousa, evitar ofuscamento das telas, e mantendo a atenção na lousa, ou no orador; fornecer cadeiras com assento ajustável, apoio de pés e braços, se possível com rodízios; disponibilizar dois tipos de lousa - quadro negro/branco para a escrita, e lousa digital para apresentações; propor layout flexível a diferentes atividades, tanto gerais como específicas adequar o mobiliário a múltiplas atividades de aprendizagem - trabalhos colaborativos, espaço pessoal e senso de convivência e de comunicação social (McVey,1996), (Nair, 2014); proporcionar espaço individual suficiente para o orador, tanto de frente à classe, como para organizar seus objetos de trabalho, e se locomover durante a fala; evitar que equipamentos ou o próprio orador dificulte a visualização da lousa; usar mesas e cadeiras leves, se possível sobre rodízios, permitindo alterar layout da sala, de acordo com as atividades; fornecer armários de uso contínuo para estudantes armazenarem pertences pessoais; Organizar espaço para expor trabalhos dos estudantes. 
Fazer gestão dos recursos de tecnologia da informação de modo democrático; manter rede de informações e de conhecimentos dentro e fora da escola, produção e compartilhamento de conteúdo; manter conexão com internet livre e constante; manter sala de aula física conectada constantemente com módulo de ensino on-line para carregamento, troca e disponibilização de conteúdo; alinhamento entre métodos de aprendizagem, recursos tecnológicos e infraestrutura física (Nou, 2016); permitir uso de recursos pessoais de acesso à internet - laptops e celulares, com finalidade educacional; produzir e compartilhar conteúdo na internet; instalar sistema de controle de condições ambientais (digital e on-line) para iluminação, sombreamento de aberturas, condicionamento de ar e recursos audiovisuais.

Fonte: As Autoras.

\section{CONCLUSÃO}

A realização desta pesquisa demonstrou inadequações ergonômicas em escolas de paises e culturas distintas. Foi possível observar que há necessidade de mais estudos, e aprofundamentos nas questões de ergonomia do ambiente construído em ambientes escolares, a fim de que possamos atualizar essas configurações espaciais a educação enriquecida com novas tecnologias.

\section{REFERENCIAS BIBLIOGRÁFICAS}

BAKER, Lindsay. What School Buildings Can Teach Us: Post-Occupancy Evaluation Surveys in K-12 Learning Environments. Dissertação de Mestrado em Arquitetura, University of California, Berkeley, 2011, 77p

GUIDALLI, C. R. R. Diretrizes para o projeto de salas de aula em universidades visando o bem- estar do usuário. Dissertação de Mestrado em Arquitetura e Urbanismo. Florianópolis, Universidade Federal de Santa Catarina, 2012.

HUANG, R. et al. The Functions of Smart Classroom in Smart Learning Age. Open Education Research, v. 2012, p. 22-27, 2012.

KAUP, M. L.; KIM, H.; DUDEK, M. Planning to Learn: The Role of Interior Design in Educational Settings. International Journal of Design for Learning, v. 4, n. 2, p. 41-55, 2013.

KOWALTOSKI, Dóris C. C. K. Arquitetura Escolar, o projeto do ambiente de ensino. São Paulo: Ed: Oficina de textos, 2011.

NAIR, Prakash. Blueprint for tomorrow. Redesigning Schools for Student-Centered Learning, Cambridge: Harvard Education Press, 2014, 207p.

OBLINGER, D. G. Learning Spaces. [s.I.] Educause e-book, 2006.

POWELL, Mikael André. Reacting to Classroom Design: A Case Study of How Corrective Actions Impact Undergraduate Teaching and Learning. Tese de Doutorado em Estudos de Educação, Lesley University, USA, 2015, 283p.

SIBILIA, Paula. Redes ou Paredes. A escola em tempos de dispersão. Rio de Janeiro: Contraponto, 2012. 222p.

TIBURCIO, T. Improving learning Environment. In: Proceedings of ICL International Conference - Ambient and Mobile Learning. AUER, M. AUER, U., MITTERMEIR, R. eds. Villach, Austria. 2005.

VILLAROUCO, V. Tratando de ambientes ergonomicamente adequados: seriam ergoambientes? In: MONT'ALVÃO, C. \& VILLAROUCO, V. Um novo olhar para o projeto: a ergonomia no ambiente construído. Rio de Janeiro: Faperj, 2AB, 2011, 184p. 25-46pp.

VILLAROUCO, Vilma. An ergonomic look at the work environment. In: Proceeding IEA 09: 17th World Congress on Ergonomics. China: Beijing, 2009. 